Berlanga, A., \& García-Peñalvo, F. J. (2005). Learning Technology Specifications: Semantic Objects for Adaptive Learning Environments. International Journal of Learning Technology, 1(4), 458-472. doi: 10.1504/IJLT.2005.007155

\title{
Learning Technology Specifications: Semantic Objects for Adaptive Learning Environments
}

Adriana Berlanga, Francisco J. García-Peñalvo

Informatics and Automatic Department, Faculty of Science, University of Salamanca,

Plaza de los Caídos S/N, 37008, Salamanca, Spain

Phone: +34 923-294400 (x1302) Fax: +34 923-294514

E-mail: solis13@usal.es,fgarcia@usal.es

\begin{abstract}
The aim of this article is to describe our work towards the definition of adaptive learning designs using learning technology specifications. To accomplish this goal, first, we introduce learning technology standards and specifications, and their purposes. Then, we present a set of the most representative learning technology specifications for describing the learning experience, namely EML, IMS LD, SCORM as well as the IEEE LOM standard, and show differences and similarities between them. Afterwards, we describe our ongoing research to define learning designs with adaptive characteristics and the authoring tool we are developing to define those learning designs. Finally, we outline conclusions and future work.
\end{abstract}

Keywords. Learning Technology Specifications, Learning Technology Standards, Metadata, Learning Objects, Learning Designs, Adaptive Educational Hypermedia Systems.

\section{Biographical notes}

Adriana Berlanga (1973) holds a degree in Computer Science (1995, Instituto Tecnologico y de Estudios Superiores de Monterrey, Mexico) and a master in Educational Technology (2001, University of Salamanca, Spain). Since 2002, she has been PhD student at the University of Salamanca and member of the Adaptive Web Engineering Group (AWEG) of the same university. Berlanga's main interests are adaptive educational hypermedia and learning technology specifications, namely IMS LD.

Francisco J. García (1971) holds a PhD in Computer Science (2000, University of Salamanca, Spain). He works as a teacher of the Informatics and Automatic Department of the University of Salamanca. Dr. García is the AWEG director. His main research interests are web engineering, semantic web, and software reuse.

\section{Introduction}

Web-based learning has raised new conceptions of the learning and teaching processes, innovative approaches for e-learning personalization, and new requirements on how elements need to be defined in order to be interoperable, reusable and exchangeable among different contexts and e-learning systems. Organizations, software vendors, and universities around the world work in the definition 
Berlanga, A., \& García-Peñalvo, F. J. (2005). Learning Technology Specifications: Semantic Objects for Adaptive Learning Environments. International Journal of Learning Technology, 1(4), 458-472. doi: 10.1504/IJLT.2005.007155

of specifications and standards that describe these requirements.

Regarding the personalization of e-learning, Adaptive Educational Hypermedia Systems is a promising field of study in this direction. These systems adjust the contents and links displayed according to the student's characteristics or learning objectives. However, one of their main drawbacks is their lack of reusability and interoperability. We claim that the use of learning technology specifications will improve the usability of this kind of systems, and will bring benefits for teachers and students.

In this article we present our ongoing research towards the definition of adaptive learning designs using learning technology specifications. We begin presenting the definition and purposes of the learning technology specifications. Subsequently, we highlight the characteristics and particularities of the Educational Modelling Language (EML) (Koper 2001), which is a valuable contribution to the specifications field, as well as specifications such as the IMS Learning Design (IMS LD 2003), the Sharable Content Object Reference Model (SCORM 2004), and the IEEE Standard for Learning Object Metadata (IEEE LOM 2002). Then, we explain our work to define adaptive learning designs using IMS LD, and we present $\mathrm{HyCo}$, the authoring tool we are developing to annotate educational elements compliant with specifications such as EML, IMS LOM (2001) -or IEEE LOM-, and IMS LD. Afterwards, we depict how HyCo is integrated in the definition of learning designs by means of a case study. Finally, we outline conclusions and future work.

\section{Learning Technology Standards and Specifications}

Learning technology standards are agreements about the characteristics a learning element, method or technique should have -no matter the hardware and software they use- in order to assure the so-called "abilities" of e-learning systems: accessibility, adaptability, affordability, durability, interoperability, manageability, and reusability (e-learning Consortium 2002; SCORM 2004).

Often, the terms standard and specification are used interchangeably. However, 
Berlanga, A., \& García-Peñalvo, F. J. (2005). Learning Technology Specifications: Semantic Objects for Adaptive Learning Environments. International Journal of Learning Technology, 1(4), 458-472. doi: 10.1504/IJLT.2005.007155

a standard is a recognized technology, format or method that has been ratified by a standard body, while a specification has not been approved by any official body. In spite of this, a specification can be de facto standard in the interim process until is ratified (Liber \& Corley 2003).

But, how does a specification become a standard? The development process starts with a contribution from a research community or user needs, such as the Open University of the Netherlands (OUNL), which created the Educational Modeling Language (EML eml.ou.nl). Then, specification consortia -such as the IMS (www.imsglobal.org) or the Aviation Industry Computer-Based Training Committee (AICC www .aicc.org) - use this input and defines a specification.

Then, the specification is evaluated and examined by users, labs, and organisations that test, prototype and customize specifications, such as the Advanced Distributed Learning (ADL www.adlnet.org) or the Canadian Core Learning Resource Metadata Protocol (CanCore www.cancore.ca).

In the next step, an accredited standard body -as the IEEE Learning Technology Standard Committee (LTSC Itsc.ieee.org) or the Learning Technology Workshop of the European Committee for Standardization (CEN/ISSS LTS www.cenorm.be/isss/workshop/lt) - reviews those tests and produces a working draft, which is officially balloted. If the draft is approved, the specification receives official certification by that organization, and becomes available through that body (e-learning Consortium 2002).

In addition, the International Standard Organization (ISO) ensures, once a standard has been accepted worldwide, its permanence. At present, there are not official learning technology standards approved by this body.

In the rest of this section we introduce learning technology specifications as EML, IMS LD and SCORM to compare them and support our decision of choosing IMS LD to define adaptive learning designs. Also, we briefly explain the IEEE LOM standard, which is a key standard for the definition of metadata resources. 
Berlanga, A., \& García-Peñalvo, F. J. (2005). Learning Technology Specifications: Semantic Objects for Adaptive Learning Environments. International Journal of Learning Technology, 1(4), 458-472. doi: 10.1504/IJLT.2005.007155

Nonetheless, the area of interest of learning technology standards extends to a wider range of e-learning aspects such as learning profiles, assessments, packages, run time communication, digital repositories, or vocabularies and glossaries.

\subsection{Educational Modelling Language (EML)}

Developed by the OUNL since 1998, EML is a notational method for e-learning environments based on a pedagogical metamodel that recognizes and separates resources from its metadata ${ }^{1}$ and from the Learning Management System (LMS) (Koper 2001).

A unit of study (UoS) is the most elaborated element in the EML design process. It is a collection of activities that are designated for one or more individuals who play a specific role in a specific learning environment. Broadly speaking, a UoS is made up by: metadata, roles (of students and support staff), learning objectives, prerequisites, content (as activities or environments), and a method of instruction. The latter, which binds structure and didactics into the UoS, groups activity structures, study methods (so-called plays), and conditions to execute the method.

\subsection{IMS Learning Design (IMS LD)}

The IMS ${ }^{2}$ organization details a framework to interchange educational elements. It has defined specifications for metadata (IMS LOM), content packaging (IMS CP 2003), assessments design (IMS QTI 2002), learner profiles (IMS LIP 2003), content sequences (IMS SS 2003), and learning designs (IMS LD), among others.

The IMS LD specification, which is based on EML, provides a consistent notation that allows authors to create many types of educational designs that can be implemented homogeneously in several courses or learning contexts. Its learning designs include learning objectives, prerequisites, roles, outcomes (learning and support activities, and activity structures), environments (learning objects and services), a method of instruction (if-then-else statements), and notifications (i.e. to send an e-mail or/and to make a learning activity active for a role). The method 
Berlanga, A., \& García-Peñalvo, F. J. (2005). Learning Technology Specifications: Semantic Objects for Adaptive Learning Environments. International Journal of Learning Technology, 1(4), 458-472. doi: 10.1504/IJLT.2005.007155

of instruction establishes which role gets which activities at what moment, to ensure learners meet their learning objectives (IMS LD 2003).

For describing metadata for learning resources, assessments, or students' characteristics other IMS specifications might be used (i.e. IMS LOM or IEEE LOM, IMS QTI, and IMS LIP).

\subsection{Sharable Content Object Reference Model (SCORM)}

SCORM (2004) -a project of the Advanced Distributed Learning ${ }^{3}$ - helps define web-based learning environments from the technical point of view. It proposes a reference model based on specifications and standards defined by other organizations using four technical books: The Overview book, the Content Aggregation Model book (SCORM CAM 2004), the Sequencing and Navigation book (SCORM SN 2004), and the Run-Time Environment book (SCORM RTE 2004).

The SCORM CAM book identifies components of the learning environment, how to package them, and how to define sequencing rules. It includes: content structure (derived from AICC/CMI 2001), metadata (from IEEE LOM), content packing (from IMS CP), and sequencing information (from IMS SS).

The SCORM SN book includes sequences for learning activity structures, sequencing strategies, and descriptions on how learner and system navigation events can be triggered and processed. It is based on IMS SS.

Finally, the SCORM RTE book integrates for run-time communication the IEEE Application Profile Interface (IEEE API 2003) and the IEEE Data Model (2003).

\subsection{IEEE Learning Object Metadata Standard (IEEE LOM)}

The IEEE LOM standard, which is based on the IMS LOM specification, defines the metadata of a learning object $\left(\mathrm{LO}^{4}\right)$ using nine categories: general, lifecycle, metametadata, technical, educational, rights, relation, annotation, classification.

Within each category different elements are grouped. For example, the educa- 
Berlanga, A., \& García-Peñalvo, F. J. (2005). Learning Technology Specifications: Semantic Objects for Adaptive Learning Environments. International Journal of Learning Technology, 1(4), 458-472. doi: 10.1504/IJLT.2005.007155

tional category gathers the following components: interactivity type, learning resource type, interactivity level, semantic density, intended end user role, context, typical age range, difficulty, typical learning time, description, and language.

At present, IEEE LOM is the only learning technology standard.

\subsection{Particularities of these Learning Technology Specifications}

Summarizing the relevant features of the learning technology specifications presented in this paper (see Table 1), we remark that:

1. SCORM is an "integrator" of other standards or specifications. It has the risk of being dependent on the standards or specifications it uses, so any change or modification in them will affect it. In addition, SCORM considers, somehow, evaluation and students' characteristics by means of its data models, but it does not provide guidance on how to design instruction or evaluation.

2. IMS LD models the learning process based on learning activities, and it is open to any learning theory ${ }^{5}$. Both features are essential to define learning experiences. However, this is a new specification and it has not been tested and used enough. In addition, IMS LD considers neither student characteristics nor evaluation; therefore these elements have to be designed with other IMS specifications (e.g. IMS LIP, IMS QTI). Another important issue is IMS LD does not give guidance to define educational contents.

3. EML, as IMS LD, designs the learning experience using learning activities, and it is open to any learning theory. It integrates aspects as activity sequence, roles, student characteristics, student tracking, and student evaluation. However, since February 2003, when the final specification of IMS LD was approved, EML has not been maintained or developed any further (Tattersall \& Koper 2003). 
Berlanga, A., \& García-Peñalvo, F. J. (2005). Learning Technology Specifications: Semantic Objects for Adaptive Learning Environments. International Journal of Learning Technology, 1(4), 458-472. doi: 10.1504/IJLT.2005.007155

Table 1 - Particularities of Learning Technology Specifications

\section{Using Learning Technology Specifications to Define Learning Designs for}

\section{Adaptive Environments}

\subsection{Adaptive Educational Hypermedia}

The objective of Adaptive Hypermedia (AH) is to adjust the content and links to each user. To reach this objective, an AH system builds a representation model of goals, preferences and knowledge for each user. During interaction, the system uses and modifies this model to adapt content and links to the needs of every user (Brusilovksy 1996).

Educational Hypermedia is one of the most popular areas of AH. An Adaptive Educational Hypermedia System (AEHS) considers the learner knowledge and verifies her/his proficiency level in the teaching topic, in order to assist the student to understand the learning material. To do so, for example, it adds or removes links, aggregates explanations or changes the presentation of the content. Some well-known examples of AEHS are InterBook (Brusilovsky et al. 1998), AHA (De Bra \& Calyi 1998), and KBS-Hyperbook (Henze \& Nejdl 1999).

\subsection{Adaptive Learning Designs (ALD)}

Our research work is focused on AEHS, specifically to propose a model to define adaptive learning designs (ALD) that will display different learning strategies to each student according to her/his knowledge and learning styles. Teachers will be provided with authoring tools to configure those learning experiences, as well as with audit tools to verify if their ALD definitions have been effective in supporting students to understand the knowledge domain. The model is based on learning technology specifications, namely IMS LD, IMS LOM and IMS CP, to define elements semantically, and guarantee their reusability and exchangeability among different AEHS (Berlanga \& García 2004b).

We decided to use IMS LD because it designs the learning process based on learning activities, is open to any learning theory, enables pedagogical diversity, 
Berlanga, A., \& García-Peñalvo, F. J. (2005). Learning Technology Specifications: Semantic Objects for Adaptive Learning Environments. International Journal of Learning Technology, 1(4), 458-472. doi: 10.1504/IJLT.2005.007155

and allows integrating learning design to more advanced e-learning applications (van Rosmalen et al. 2004). In addition, some elements of IMS LD can be useful to adapt activities. For instance, the element <activities> contains attributes that can facilitate adaptivity performance as isvisible, to hide or show activities, or number-to-select, to track the activities that have to be completed. Also, elements as $<$ conditions $>$ and $<$ properties $>$ can help to adjust the learning design to particular prerequisites and attributes.

\subsection{HyCo: Towards an Authoring Tool to Define ALD}

In order to implement the model we are developing, we need an ALD authoring tool. Our objective is twofold. We want to verify if our proposal for the definition of ALD is feasible, but also, we intend to test if their reusability and exchangeability among AEHS is possible by means of learning technology specifications.

We decided to take advantage of the Hypermedia Composer (HyCo) (García \& García 2005) and expand its features in order to use it as the ADL authoring tool. Until now, this tool is able to produce learning resources compliant with EML and IMS LOM (or IEEE LOM). Nowadays, we are developing the interface to create learning designs compliant with IMS LD. Afterwards we will include adaptive features to these learning designs.

In the rest of this section we briefly introduce HyCo and its relation with learning technology specifications.

\subsubsection{The Hypermedia Composer (HyCo)}

The main goal of HyCo is the creation of hypermedia books or educational contents independently of their publication format. Hence, HyCo is fully compliant with the Semantic Web (Berners-Lee et al. 2001) notion where a clear separation between the content, its presentation, and its metadata exists. Each document is divided into semantic units that will be further formatted to be used, for instance, in a web-based course, in a multimedia CD-ROM, or in a self-distributed PDF (Portable Document Format) file. In this way, the teacher writes the content once, 
Berlanga, A., \& García-Peñalvo, F. J. (2005). Learning Technology Specifications: Semantic Objects for Adaptive Learning Environments. International Journal of Learning Technology, 1(4), 458-472. doi: 10.1504/IJLT.2005.007155

and has the possibility of reusing it.

HyCo uses an internal XML-based format (Bray et al. 2004) to store the educational contents. This format allows the use of learning technology specifications in this authoring tool.

\subsubsection{HyCo and EML}

In a first approach we decided to include in HyCo the possibility to generate for each book, or resource, an output file tagged according to EML, and vice versa, the option to upload an EML input file that can be seen as HyCo content. To download the file it is compulsory to indicate learning objectives, prerequisites, and roles (that are not part of HyCo but defined in EML), in such way that a HyCo book or chapter becomes a basic UoS of EML.

However, since EML has not been maintained any further, we decided to change to IMS LD. The first step was the creation of semantic learning objects compliant with IMS LOM (or IEEE LOM) in order to add them later on into learning designs. In addition, by doing so, we ensure the resources created in HyCo could be reused and exchanged as learning objects among different authors and systems.

\subsubsection{HyCo and IMS LOM}

HyCo can convert every section of every e-book, or educational resource, into a learning object. To create them HyCo executes a two-step process. In the first step, an automatic process sets all the IMS LOM metadata elements that can be inferred from other data or that are liable to have default values. Figure 1 shows and example of these elements.

Figure 1. Examples of the IMS LOM elements that HyCo sets automatically

Once this process is over, HyCo displays the IMS LOM Editor (see Figure 2). By means of this editor, authors can verify and modify the metadata automatically generated, as well as add the necessary metadata to complete the record. 
Berlanga, A., \& García-Peñalvo, F. J. (2005). Learning Technology Specifications: Semantic Objects for Adaptive Learning Environments. International Journal of Learning Technology, 1(4), 458-472. doi: 10.1504/IJLT.2005.007155

Figure 2. HyCo IMS LOM Editor

When the two-step process finishes, a XML file is generated for each new learning object (each one of them correspond to each book, section or subsection of the book) and stored them in an IMS LOM repository. This repository will allow us to have learning objects that can be attached to IMS LD learning activities.

\subsubsection{HyCo and IMS LD}

In HyCo authors describe their learning designs using the elements of IMS LD. We defined an authoring process that gathers three definitions: learning resources, learning components, and learning methods.

The definition of learning resources uses the HyCo two-step process we already mentioned that describes learning objects (HyCo IMS LOM Editor).

The definition of learning components includes:

- Roles. To specify the parts involved in the learning design (i.e. learner and staff). It includes elements as title, metadata and information.

- Learning activities. To describe the activities that will be performed. It includes elements as properties, learning objectives, prerequisites, description, and feedback. Figure 3 shows the HyCo interface to define a learning activity.

- Activity structures. To group learning activities in sequences or selections.

Figure 3. HyCo IMS LD Editor

The learning method definition aims at describing the "learning flow" of the learning design by connecting roles to learning activities, or activity structures, and delimiting under what conditions tasks will be considered as complete, as well as possible actions after that.

Finally, the learning design integrates the learning method, learning components, metadata, and general prerequisites and objectives.

It is important to mention that in HyCo elements as roles, learning objectives, or prerequisites are defined as separate objects. This makes them elements that can be included into different learning activities or learning designs. 
Berlanga, A., \& García-Peñalvo, F. J. (2005). Learning Technology Specifications: Semantic Objects for Adaptive Learning Environments. International Journal of Learning Technology, 1(4), 458-472. doi: 10.1504/IJLT.2005.007155

\section{IMS Learning Designs into Practice: a Case Study}

In this section we use a case study to explain how HyCo is integrated in the process of creating a learning design compliant with IMS LD.

First, professors should outline the learning design. The Best Practice and Implementation Guide of IMS LD (2003) divides this task into six phases:

1. Identify learning activities and support activities, label and list them sequentially.

2. Identify different roles (student, teacher, manager, etc.).

3. Look at the activities and see if they run in a sequential or in an alternative way. Identify conditions and properties, and notifications. Diagram activities using UML symbols.

4. Group activities. Indicate if they follow each one sequentially or if there is a choice.

5. Identify role-parts and decide if they have to be synchronized between the start point and the end point. Activities between the fork and join belong to a separate act.

6. Decide if more than one play needs to be used (e.g. alternative didactic scenarios).

As an example, we will take the vocational career of Hotel, Catering Trade and Tourism of a Chef programme. This programme has 2000 class hours, and it is divided into two modules. Each module has six courses. The second-modulecourse "Bakery and Confectionery" has six lessons. We will take the lesson "desserts" to follow the IMS LD design guidelines described above.

1. Activity structure of the course

1.1. Introduction: Classification and description of desserts.

1.2. Lessons: Simple techniques: Simple desserts; Advanced techniques: (i) Hot desserts; (ii) Cold desserts.

1.3. Procedures: (i) Simple desserts; (ii) Hot desserts; (iii) Cold desserts.

1.4. Tests: (i) Writing; (ii) Practical.

2. There is just one role (Student).

3. Figure 4 represents the UML activity diagram of the lesson.

4. There are some considerations regarding activity sequence:

4.1 An introductory lesson is mandatory and has to be read before any other content. 
Berlanga, A., \& García-Peñalvo, F. J. (2005). Learning Technology Specifications: Semantic Objects for Adaptive Learning Environments. International Journal of Learning Technology, 1(4), 458-472. doi: 10.1504/IJLT.2005.007155

4.2 Simple techniques lesson should follow the introductory lesson. Any other part of the content cannot be read at this point.

4.3 Advanced techniques lessons can begin either with hot desserts or cold desserts. It is mandatory to read these lessons before going to the next phase (procedures).

4.4 Procedures are not sequentially structured, they can be read in any order, but they need to be completed before going on to the next phase (tests).

4.5 Test phase starts with a writing test followed by a practical test.

5. There is just one Act because there is just one role.

6. There is just one Play because there is just one didactic scenario.

Once professors outline their learning design, they might set up the connection between the design and IMS LD. Following the example, an extract of the desserts lesson could be defined as ${ }^{6}$ :

- Role: Student (R-learner)

- Learning objective (general): To be able to elaborate desserts. The resource "RES-ElabDes" contains the learning objective.

- Prerequisites (general): To read a pre-introductory text. The resource "RESPreDess" contains the text.

- Learning resources: Define the learning resources that will be included in the learning activities (e.g. text, images, graphs, etc.).

- Learning activities: (i) Classification and description (LA-class-dess); (ii) Techniques to elaborate simple desserts (LA-simple-dess), (ii) Techniques to elaborate advanced desserts (LA-hot-dess; LA-cold-dess).

- Activity structure: (i) Introduction and then simple techniques (AS-intro); (ii) Advanced techniques any order (AS-advanced-techniques).

Figure 4. UML activity diagram of the desserts lesson

Then, professors can create their learning designs using HyCo. The tool will automatically generate the XML document instance for the desserts lesson using the IMS LD notation. Figure 5 shows part of the XML document that HyCo will generate.

Figure 5. Case of study: the definition of the desserts lesson using IMS LD

If the professors want to exchange a complete IMS unit of learning, HyCo will use the IMS CP manifest to include the IMS LD XML into the <organizations> IMS CP element, and the identification and location of resources (e.g. RES- 
Berlanga, A., \& García-Peñalvo, F. J. (2005). Learning Technology Specifications: Semantic Objects for Adaptive Learning Environments. International Journal of Learning Technology, 1(4), 458-472. doi: 10.1504/IJLT.2005.007155

ElabDes, RES-cold-dess, etc.) into the <resources $>$ IMS CP element.

\section{Conclusions and Future Work}

Undoubtedly, learning technology specifications are in their early phases of development. Their long term success depends on their quality, practical utility, and value in the real world (Walker 2003) ${ }^{7}$. Nevertheless, they might be considered as the next stage in the evolution of the e-learning field since they will enhance e-learning attributes such as exchangeability, reusability, accessibility, and adaptability. In addition, the semantic definition of learning methods and resources might improve the personalization of e-learning environments.

In this paper we introduced our work towards the semantic definition of adaptive learning designs using learning technology specifications. We also depicted HyCo, the authoring tool we are developing to define these learning designs.

Our future work is to add different features into HyCo that will make possible the generation of ALD. First, we will incorporate in the definition of learning activities the learning style they endorse and in what proportion. We claim that in order to adjust the learning designs, both the learning style of the activities and the

learning style of the students must be taken into consideration. To date, we have developed a proposal to extend IMS LD, by using the <itemmodel> element, to incorporate the learning style (Berlanga \& García 2004a).

Then, we will include in the authoring of the learning method the option to create adaptive rules that will adjust the learning design to learner's knowledge and learning styles. We will incorporate a formalism we have developed for the definition of adaptive rules, which uses a collection of sets based mostly on the IMS LD element <conditions> (Berlanga \& García 2004a). Our goal is to provide professors a formalism to describe their own adaptive rules that, on one hand, facilitates the authoring of the rules and, on the other hand, makes their reutilization possible among different AEHS compliant with IMS LD.

Finally, we plan to work with teachers of different contexts (i.e. university, vocational schools, and informal education) to test if they find HyCo user-friendly 
Berlanga, A., \& García-Peñalvo, F. J. (2005). Learning Technology Specifications: Semantic Objects for Adaptive Learning Environments. International Journal of Learning Technology, 1(4), 458-472. doi: 10.1504/IJLT.2005.007155

and helpful to define adaptive learning designs, check if HyCo can reuse other learning designs compliant with IMS LD, and test the interoperability among learning designs with adaptive characteristics.

\section{Acknowledgments}

Adriana Berlanga thanks the Mexican Council of Science and Technology (CONACyT) for its support. Research supported by the Government of Castile and Lion (Projects ref. SA017/02, US09/05).

\section{References}

AICC/CMI 2001, Instruction Guidelines for Interoperability (CMIO01) v.3.5. Aviation Industry CBT Committee (AICC). Retrieved: November 20, 2004, from http://www.aicc.org/docs/tech/cmi001v3-5.pdf

Berlanga, A. \& García, F.J. 2004a, 'An Open Model to define Adaptive Educational Hypermedia Systems based on Learning Technology Specifications', in $3^{\text {rd }}$ Int. Workshop on Web Semantics, WebS 2004, in conjunction with $15^{\text {th }}$ Int. Database and Expert Systems Applications, DEXA 2004. IEEEE Press, pp. 198-202.

Berlanga, A. \& García F.J. 2004b, 'Towards Adaptive Learning Designs', in P. De Bra and W. Nejdl (eds), Adaptive Hypermedia and Adaptive Web-Based Systems, $3^{\text {rd }}$ International Conference Proceedings, LNCS Springer-Verlag, vol. 3137, pp. 372-375.

Berners-Lee, T., Hendler, J. \& Lassita, O. 2001, 'The Semantic Web', Scientific American, May 2001.

Best Practice and Implementation Guide 2003, IMS LD, Retrieved: November 20, 2004, from http://www.imsglobal.org/learningdesign/ldv1p0/imsld bestv1p0.html

Bray, T., Paoli, J., Sperberg-MacQueen, C. M., Maler, E. \& Yergeau, F. 2004, Extensible Markup Language (XML) v.1.0 ( $3^{\text {rd }}$ Edition). World Wide Web Consortium Recommendation. Retrieved: November 20, 2004, from http://www.w3.org/TR/2004/RECxml-20040204.

Brusilovsky, P. 1996, 'Methods and techniques of adaptive hypermedia', User Modeling and User Adapted Interaction, vol.2-3, pp. 87-129.

Brusilovsky, P., Eklund, J. \& Schwarz, E. 1998, 'Web-based education for all: A tool for developing adaptive courseware', in $7^{\text {th }}$ International World Wide Web Conference, Computer Networks and ISDN Systems, vol. 30 no. 1-7, pp. 291-30.

De Bra, P. \& Calvi, L. 1998, 'AHA: a Generic Adaptive Hypermedia System', in $2^{\text {nd }}$ Workshop on Adaptive Hypertext and Hypermedia, ACM Hypertext. pp. 1-10. Retrieved: November 20, 2004, from http://wwwis.win.tue.nl/ah98/DeBra.html.

e-learning Consortium 2002, Making sense of learning specifications and standards, S3 WG Masie Center. Retrieved: November 20, 2004, from http://www.masie.com/standards/S3_Guide.pdf

Friesen, N. 2003, 'Three Objections to Learning Objects', in R. McGreal (ed), Online education using learning objects, Taylor \& Francis Books Ltd, London.

García, F. \& García, J. 2005, 'Educational Hypermedia Resources Facilitator', Computers \& Education, vol. 44, no. 3, pp. 301-325 (in press). 
Berlanga, A., \& García-Peñalvo, F. J. (2005). Learning Technology Specifications: Semantic Objects for Adaptive Learning Environments. International Journal of Learning Technology, 1(4), 458-472. doi: 10.1504/IJLT.2005.007155

Henze, N. \& Nejdl, W. 1999, 'Adaptivity in the KBS-Hyperbook System', in $2^{\text {nd }}$ Workshop on Adaptive Systems and User Modeling, WWW Conference. Retrieved: November 2, 2004, from http://wwwis.win.tue.nl/asum99/henze/henze.html

Hodgins, W. (2004) 'Into the Future of Learning Objects', in Workshop on e-learning Objects \& Systems. Retrieved: November 2, 2004, from http://grove.ufl.edu/ pgl/events/Hodgins/future_lo.pdf

Hummel, H., Manderveld, J., Tattersall, C. \& Koper, R. 2004, 'Educational modelling language and learning design: new opportunities for instructional reusability and personalised learning', Int. J. Learning Technology, vol. 1, no. 1, pp. 111-126.

IEEE API 2003, IEEE 1484.11.2-2003 Standard for Learning Technology. API for Content to Runtime Services Communication. Retrieved: November 20, 2004, from http://jtc1sc36.org/doc/36N0804.pdf

IEEE Data-Model 2003, IEEE P1484.11.1 Draft Standard for Learning Technology. Data Model for Content Object Communication. Retrieved: November 20, 2004, from http://jtc1sc36.org/doc/36N0805.pdf

IEEE LOM 2002, IEEE 1484.12.1-2002. Standard for Learning Object Metadata. IEEE Inc, New York.

IMS CP 2003, Content Packaging specification v1.1.3. Retrieved: November 20, 2004, from http://www.imsglobal.org/content/packaging/index.cfm

IMS LD 2003, Learning Design specification v1. Retrieved: November 20, 2004, from http://www.imsglobal.org/learningdesign/index.cfm

IMS LIP 2003, Learner Information Package specification v1. Retrieved: November 20, 2004, from http://www.imsglobal.org/profiles/index.cfm

IMS LOM 2001, Learning Resource Metadata specification v1.1.2. Retrieved: November 20, 2004, from http://www .imsglobal.org/metadata/index.cfm

IMS QTI 2002, Questions and Test Interoperability specification. v1 .2.1. Retrieved: November 20, 2004, from http://www.imsglobal.org/question/index.cfm

IMS SS 2003, Simple Sequencing specification v1.0. Retrieved: November 20, 2004, from http://www.imsglobal.org/simplesequencing/index.cfm

Koper, R. 2001, Modelling units of study from a pedagogical perspective. The pedagogical metamodel behind EML. Retrieved: November 20, 2004, from http://eml.ou.nl/introduction/docs/ped-metamodel.pdf

Liber, O. \& Corley, L. 2003, 'Learning Technology Standards - Where's The Pedagogy?', in A. Méndez-Vilas et al. (eds), $2^{\text {nd }}$ Int. Conference on Multimedia and ITC in Education, $m$-ICTE2003, Junta de Extremadura , Spain, pp. 855-859.

Rehak, D. 2004, 'Good \& Plenty, Googlezon, Your Grandmother and Nike: challenges for ubiquitous learning \& learning technology', in Workshop on e-learning Objects \& Systems. Retrieved: June 20, 2004, from http://grove.ufl.edu/ pgl/events/Rehak/googlezon.pdf

van Rosmalen, P., Brouns, F., Tattersall, C., Vogten, H., van Bruggen, J., Sloep, P. \& Koper, R. 2004, Towards an open framework for adaptive, agent-supported e-learning. Retrieved: November 2, 2004, from http://hdl.handle.net/1820/76

SCORM 2004, Sharable Content Object Reference Model v1.3 Retrieved: November 20, 2004, from http://www.adlnet.org

SCORM CAM 2004, Content Aggregation Model v1.3. Retrieved: November 20, 2004, from http://www.adlnet.org

SCORM RTE 2004, Run-Time Environment v1.3. Retrieved: November 20, 2004, from 
Berlanga, A., \& García-Peñalvo, F. J. (2005). Learning Technology Specifications: Semantic Objects for Adaptive Learning Environments. International Journal of Learning Technology, 1(4), 458-472. doi: 10.1504/IJLT.2005.007155

http://www.adlnet.org

SCORM SN 2004, Sequencing and Navigation v1.3. Retrieved: November 20, 2004, from http://www.adlnet.org

Tattersall, C. \& Koper, R. 2003, 'EML and IMS Learning Design: from LO to LA', Learning \& Teaching Support Network. Retrieved: November 20, 2004, from http://www.ltsn.ac.uk/embedded_object.asp?id=18611

Walker, E. 2003, 'Session introduction', in eLearning Results2003 Conference, Retrieved: May 2, 2004, from http://www .elearningresults.com/old/html/summit.php

Wiley, D. 2000, 'Connecting learning objects to instructional design theory: A definition, a metaphor, and a taxonomy', in D. Wiley (ed), The Instructional Use of Learning Objects. Retrieved: May 2, 2004, from http://reusability.org/read/chapters/wiley.doc

${ }^{1}$ Metadata (i.e. data about data) identifies the attributes of an element, resource, object, or person.

${ }^{2}$ IMS (www.imsglobal.org) is a non-profit organization of different universities, companies and organizations that supports the adoption and use of learning technology worldwide.

${ }^{3}$ Advanced Distributed Learning (ADL, www.aicc.org) is an initiative of the USA Department of Defence to promote cooperation between stakeholders to develop e-learning standardization.

${ }^{4}$ IEEE LOM defines a LO as "Any entity, digital or non-digital, that may be used for learning, education or training". Other definitions of the term can be found in Wiley (2000) and Hummel et al. (2004).

${ }^{5}$ However, there is skepticism about pedagogical neutrality. Friesen (2003) argues standards cannot be pedagogically neutral, if they are so, they cannot be at the same time pedagogically significant.

${ }^{6}$ Prefixes of the official use of titles are used to identify elements (i.e. LA for learning activities).

${ }^{7}$ Hodgins (2004) stress the importance of mechanisms that automatically generate metadata and intelligent data management. Rehak (2004) claims for user-friendly tools to search and deliver LO similar to those defined for business (e.g. Amazon, Google, eBay)

Table 1 - Particularities of Learning Technology Specifications

\begin{tabular}{|c|c|c|c|}
\hline & SCORM v1.3 & IMS LD v1 & EML \\
\hline Focus on & $\begin{array}{l}\text { Content structures and } \\
\text { content sequences }\end{array}$ & Learning designs & Units of study \\
\hline $\begin{array}{l}\text { Learning Process } \\
\text { Modelling }\end{array}$ & \begin{tabular}{|l|}
$\begin{array}{l}\text { To some extent (activities, } \\
\text { objectives) }\end{array}$ \\
\end{tabular} & $\begin{array}{l}\text { Learning } \\
\text { activities }\end{array}$ & $\begin{array}{l}\text { Learning } \\
\text { activities }\end{array}$ \\
\hline $\begin{array}{l}\text { Learning } \\
\text { Theory }\end{array}$ & $\begin{array}{l}\text { Its flexibility allows a varie- } \\
\text { ty of learning design ap- } \\
\text { proaches }\end{array}$ & Open to any learning theory & Open to any learning theory \\
\hline $\begin{array}{l}\text { Pedagogical } \\
\text { Characteristics }\end{array}$ & $\begin{array}{l}\text { - Objectives associated } \\
\text { with Sharable Content } \\
\text { Objects (SCO) in the Data } \\
\text { Model } \\
\text { - Activities } \\
\text { - Those derived form IEEE } \\
\text { LOM (e.g. type of interac- } \\
\text { tion) }\end{array}$ & $\begin{array}{l}\text { - Prerequisites } \\
\text { - Objectives } \\
\text { - Method } \\
\text { - Components (e.g. activi- } \\
\text { ties, sequences) } \\
\text { - Those derived form IEEE } \\
\text { LOM }\end{array}$ & $\begin{array}{l}\text { - Prerequisites } \\
\text { - Objectives } \\
\text { - Method } \\
\text { - Activity } \\
\text { - Sequence } \\
\text { - Roles }\end{array}$ \\
\hline $\begin{array}{l}\text { Content } \\
\text { Structure }\end{array}$ & $\begin{array}{l}\text { Assets; SCO; Content } \\
\text { Organization }\end{array}$ & None & Unit of study \\
\hline $\begin{array}{l}\text { Student } \\
\text { Characteristics }\end{array}$ & $\begin{array}{l}\text { To some extent. Preferences } \\
\text { (Data Model) can be used }\end{array}$ & $\begin{array}{l}\text { No } \\
\text { (IMS LIP can be used) }\end{array}$ & Yes \\
\hline Student tracking & Yes & Yes & Yes \\
\hline $\begin{array}{l}\text { Student } \\
\text { Evaluation }\end{array}$ & $\begin{array}{l}\text { To some extend. Score } \\
\text { (Data Model) can be used }\end{array}$ & $\begin{array}{l}\text { No } \\
\text { (IMS QTI can be used) }\end{array}$ & Yes \\
\hline
\end{tabular}


Berlanga, A., \& García-Peñalvo, F. J. (2005). Learning Technology Specifications: Semantic Objects for Adaptive Learning Environments. International Journal of Learning Technology, 1(4), 458-472. doi: 10.1504/IJLT.2005.007155

\begin{tabular}{|l|l|l|l|}
\hline $\begin{array}{l}\text { Part of a standard } \\
\text { /spec. collection }\end{array}$ & No & Yes & No \\
\hline Test suite & Yes & No & Yes ("player") \\
\hline Communication & Web-based & Web-based & Web-based \\
\hline Defined by & $\begin{array}{l}\text { Blend (US government, } \\
\text { academia, vendors, AICC, } \\
\text { IEEE LTSC, IMS) }\end{array}$ & $\begin{array}{l}\text { Blend (academia, vendors, } \\
\text { IEEE LTSC, ADL) }\end{array}$ & Academia \\
\hline $\begin{array}{l}\text { Year of } \\
\text { Approval }\end{array}$ & 2004 & 2003 & Never \\
\hline
\end{tabular}

Figure 1. Examples of the IMS LOM elements that HyCo sets automatically

$<$ general $>:<$ title $>=$ HyCo. Book. Title or HyCo. Section.Title

$\langle$ general $\rangle:\langle$ language $\rangle=\mathrm{HyCo}$.User language

$\langle$ general $>:<$ structure $>=$ IF HyCo. Book = "Collection"; IF HyCo.Section = "Atomic"

$<$ general $>$ : $<$ aggregationlevel $>=$ "3"

$\langle$ lifecycle $\rangle:\langle$ contribute $\rangle:\langle$ role $\rangle=$ "Author"

$<$ lifecycle $>:<$ contribute $>$ : $\langle$ centity $\rangle=$ HyCo.UserName

$<$ relation $>$ : $<$ kind $>$ : $\langle$ value $>$ :

If HyCo.Section or HyCo.Subsection Then $<$ relation $>:<k$ ind $>:<$ value $>=$ "IsPartOf"

If HyCo.Glossary Then $<$ relation $>:<$ kind $>:<$ value $>=$ "IsReferencedBy"

If $\mathrm{H}$ YCo.References Then $<$ relation $>$ : $<$ kind $>$ : $<$ value $>=$ "References"

If HyCo.Link Then <relation $>:<$ kind $>$; $<$ value $>=$ "IsReferenced By"

Figure 2. HyCo IMS LOM Editor

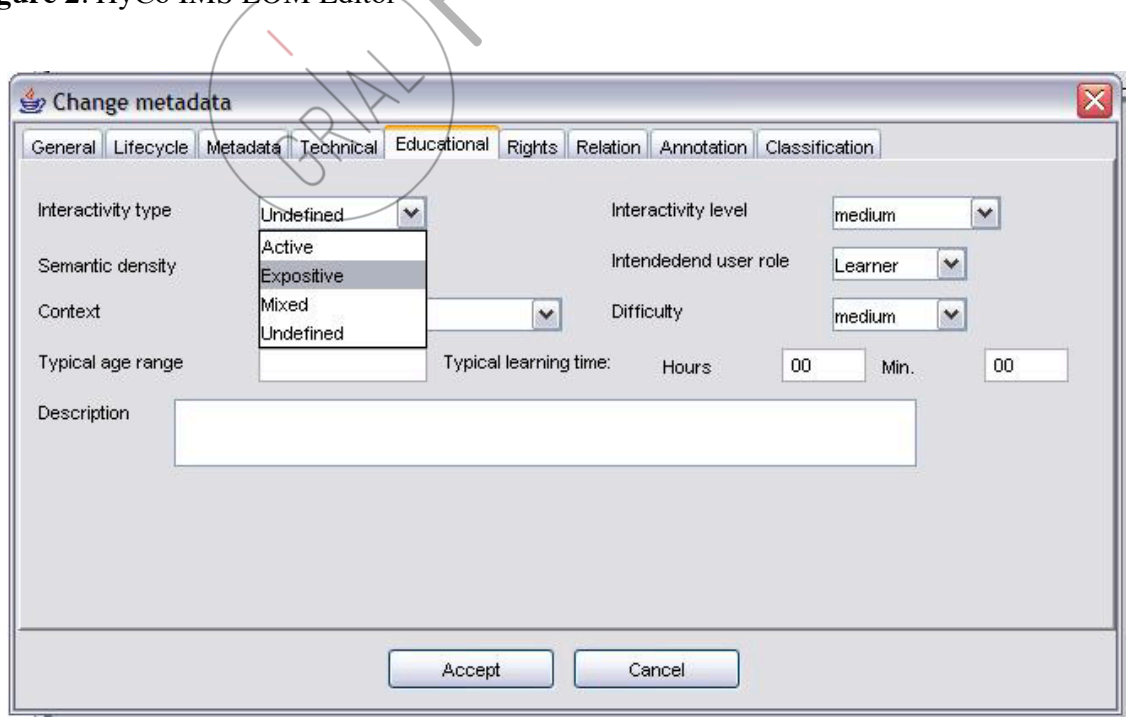


Berlanga, A., \& García-Peñalvo, F. J. (2005). Learning Technology Specifications: Semantic Objects for Adaptive Learning Environments. International Journal of Learning Technology, 1(4), 458-472. doi: 10.1504/IJLT.2005.007155

Figure 3. HyCo IMS LD Editor

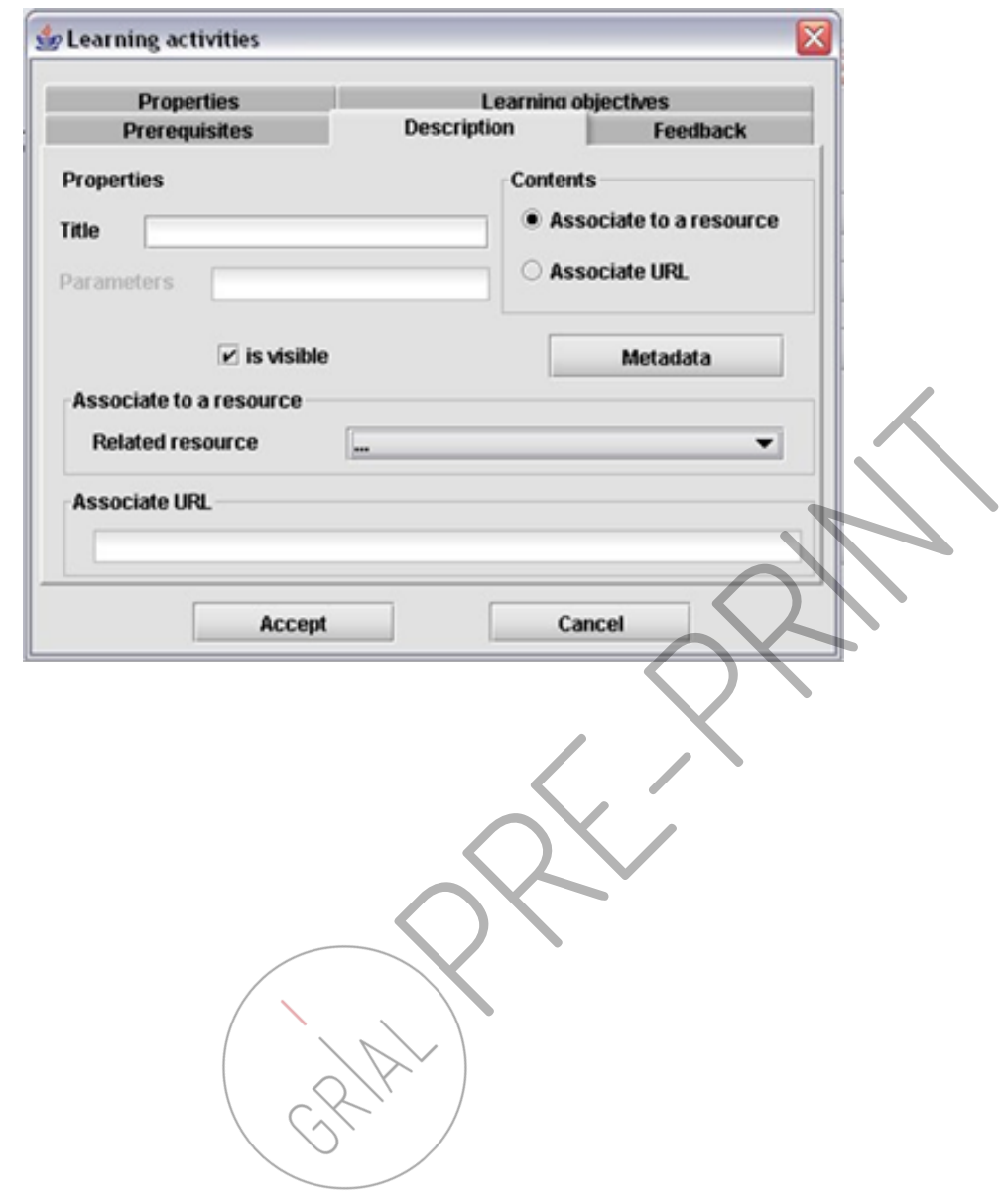


Berlanga, A., \& García-Peñalvo, F. J. (2005). Learning Technology Specifications: Semantic Objects for Adaptive Learning Environments. International Journal of Learning Technology, 1(4), 458-472. doi: 10.1504/IJLT.2005.007155

Figure 4. UML activity diagram of the desserts lesson

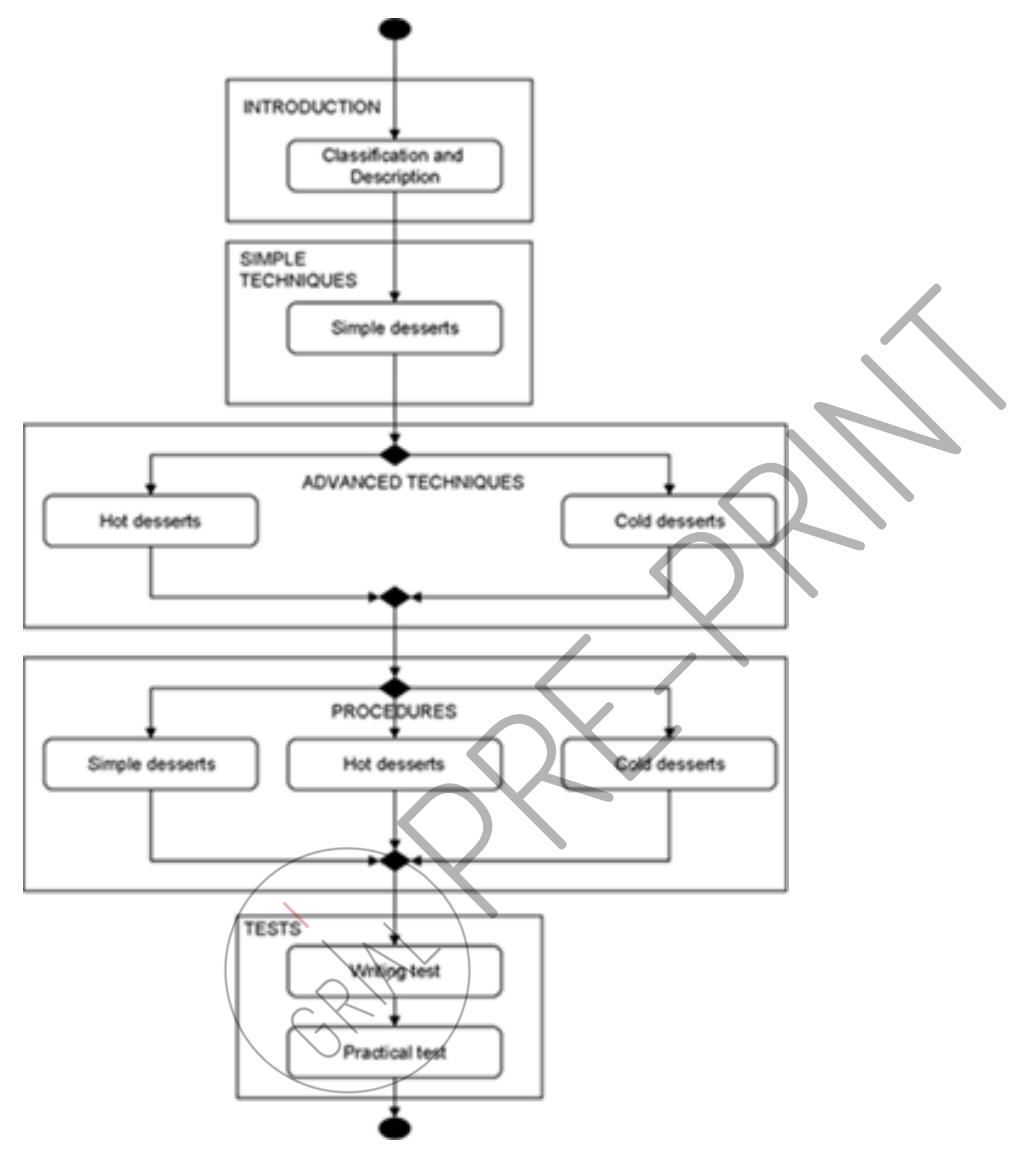


Berlanga, A., \& García-Peñalvo, F. J. (2005). Learning Technology Specifications: Semantic Objects for Adaptive Learning Environments. International Journal of Learning Technology, 1(4), 458-472. doi: 10.1504/IJLT.2005.007155

Figure 5. Case of study: the definition of the desserts lesson using IMS LD

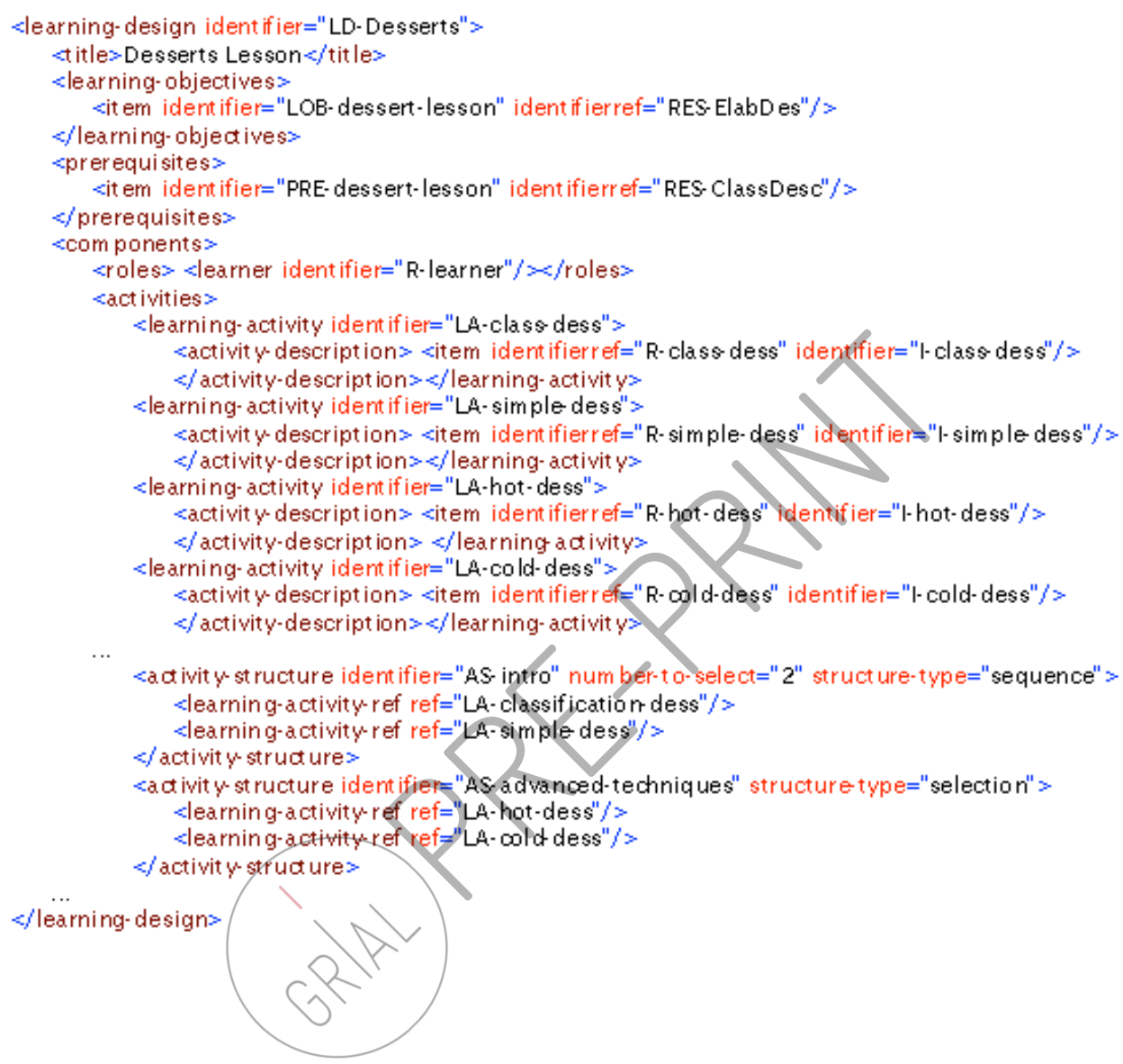

